\title{
VALORIZAÇÃO E FORMAÇÃO DOS PROFESSORES PARA A EDUCAÇẨO BÁSICA: QUESTÕES DESAFIADORAS PARA UM NOVO PLANO NACIONAL DE EDUCAÇÃO
}

\author{
LEDA SCHEIBE*
}

\begin{abstract}
RESUMO: Após um breve balanço da situação que diz respeito à valorização e formação dos professores destinados à educação básica no Brasil, o presente artigo propõe-se a colaborar com esta discussão, abordando algumas das questóes desafiadoras que se colocam para a melhoria deste campo de trabalho, bem como os principais embates que suscitam tais proposições. São considerados, particularmente, os encaminhamentos mais gerais já propostos pelas conferências nacionais - CONEB (2008) e CONAE (2010) - e, ainda, pelo documento do CNE para o novo Plano Nacional de Educação ( $\mathrm{PNE}$ ), relativo ao período de 2011 a 2020. Conclui-se que cabe ao novo PNE estabelecer prioridades para que continue o trabalho que hoje amplia a valorização e a formação desejada, corrigindo percursos, introduzindo novas ações e formulações legislativas e abrindo, cada vez mais, as possibilidades de participação do coletivo educacional para a formulação dos encaminhamentos necessários.
\end{abstract}

Palavras-chave: Formação de professores. Educação básica. Plano Nacional de Educação. Valorização docente.

BASIC EDUCATION TEACHERS' TRAINING AND VALUATION: CHALLENGING QUESTIONS FOR THE NEW NATIONAL PLAN FOR EDUCATION

ABSTRACT: After briefly assessing the valuation and training of basic education teachers in Brazil, this paper seeks to contribute to this discussion by addressing some of the challenging questions posed to

Doutora em Educação, professora-titular emérita da Universidade Federal de Santa Catarina (UFSC) e do Programa de Pós-Graduação em Educação da Universidade do Oeste de Santa Catarina (UNOESC).E-mail: 1scheibe@uol.com.br 
improve this field, as well as the major struggles that resulted from such proposals. The orientations proposed by the national conferences - CONEB, 2008, and CONAE, 2010 - and the CNE's document for the new 2011-2020 National Plan for Education are especially considered. We conclude that the new PNE will have to set priorities so that the work of broadening the desired valuation and training can continue. Among such priorities are: correcting paths, introducing new actions and legislative formulations, and opening more opportunities for the collective participation of educators in the orientation of this process.

Key words: Teachers' training. Basic education. National Plan for Education. Teacher's valuation.

\section{Introdução}

$\mathcal{E}$

m 2010 termina a vigência do atual Plano Nacional de Educação (PNE, Lei n. 10.172, de 9 de Janeiro de 2001). O novo Plano, que deve reestruturar a participação da União no planejamento da educação nos próximos dez anos, está sendo construído. Para tal construção, no entanto, o ponto de partida são os problemas já identificados e mesmo os avanços já conquistados; sobretudo, parte-se da certeza de que mesmo os avanços trazem novos desafios. Uma leitura daquilo que é hoje nos possibilita dizer com maior clareza o que se pretende para o futuro. O momento da construção do PNE é, pois, o momento da sociedade dizer o que deve ser.

O presente artigo pretende colaborar com esta discussão, abordando algumas das questóes desafiadoras que se colocam para a melhoria deste campo de trabalho, bem como os principais embates que suscitam. Após situar um panorama geral do campo, são consideradas para análise as indicaçôes para elaboração do novo PNE, relativo ao período de 2011 a 2020. As indicaçōes referem-se, particularmente, àquelas que partiram dos eventos nacionais - Conferência Nacional da Educação Básica (CONEB), realizada em 2008 (CONEB, 2008), e Conferência Nacional da Educação (CONAE), realizada em 2010 (CONAE, 2010), bem como de um documento do Conselho Nacional de Educação (CNE): Portaria CNE/CP n. 10, de 6 de agosto de 2009. 


\section{O cenário de uma profissão que precisa ser valorizada}

Com base no Censo Escolar de 2007, em estudo recentemente publicado pelo Instituto Nacional de Estudos e Pesquisas Educacionais Anísio Teixeira (INEP) (Brasil/MEC/INEP, 2009), o Brasil contava então com 1.882 .961 de professores vinculados à educação básica, dos quais 1.288 .688 com nível superior completo $(68,4 \%$ do total). Destes, pelo menos $10 \%$ não possuem curso de licenciatura e um número expressivo de professores, mesmo com licenciatura, não tem a formação compatível com a disciplina que lecionam. É nos anos finais do ensino fundamental, etapa de ensino na qual as matérias começam a ser dadas por professores de áreas específicas e no ensino médio que esta proporção é maior. Os números revelam também que a maior distorção está na área de Ciências Exatas, na qual os profissionais formados nos cursos de licenciatura do país são insuficientes para suprir a demanda.

Ainda com dados do Censo Escolar de 2007, o INEP apresentou um perfil dos professores e professoras brasileiros da educação básica (Brasil/INEP, 2009), no qual outras informaçôes sobre as características destes profissionais podem ser visualizadas, tais como:

- cerca de $82 \%$, ou seja, mais de um milhão e meio de docentes em regência de classe eram mulheres, perfil que varia à medida que se tomam como referência os diversos níveis da educação básica, da educação infantil ao ensino médio e educação profissionalizante;

- a média de idade é de 38 anos;

- predomina o docente que atua em uma só escola, cerca de $80 \%$, e em um só turno, cerca de $63 \%$;

- $83 \%$ trabalham em escola urbana;

- cerca de $84 \%$ da população docente trabalha na rede pública de ensino, em escolas federais, estaduais ou municipais, em uma ou mais destas redes;

- quanto ao nível da escolaridade, cerca de $68 \%$ do total dos docentes recenseados em 2007 possuíam diploma de nível superior completo; 
Valorização e formação dos professores para a educação básica...

- quanto às áreas de formação com maior número de professores em relação ao total de docentes, foi possível registrar 30\% formados em Pedagogia; 12\% em Letras/Literatura/Língua Portuguesa; 7,5\% em Matemática e 6,4\% em História.

A inexistência de um Sistema Nacional de Educação no Brasil pode ser uma das razões pelas quais a profissão docente se apresenta, hoje, extremamente diferenciada e fragmentada. Estados e municípios, considerados entes autônomos, conforme a Constituição Federal de 1988, correspondem cada um a um sistema de ensino. Há professores federais, estaduais e municipais; professores concursados e não concursados; professores urbanos e rurais; professores das redes pública e particular e das redes patronais profissionais (Sistema S); e professores titulados e sem titulação. Essa situação origina planos de carreira distintos (ou ausência de planos), salários diferenciados e duplicação de jornada em carreiras diferentes: estadual/municipal; pública/privada; educação básica/educação superior (Oliveira, 2010).

As pesquisas sobre a profissão de professor revelam exaustivamente uma série de problemas e desafios para a elevação do estatuto socioeconômico da categoria, destacando-se, dentre outros aspectos: os baixos salários predominantes; e a deterioração das condições de trabalho, esta decorrente das longas jornadas, de salas superlotadas, do crescimento da indisciplina e da violência na escola, da dificuldade em realizar atualizações de conteúdo e metodológicas, das cobranças de maior desempenho profissional (Oliveira \& Feldfeber, 2006). Já no que concerne à formação de professores, a fragmentação institucional ${ }^{1}$ é clara. Segundo o Censo da Educação Superior de 2007 (Brasil/IneP, 2009 b), é o setor privado que responde por cerca de $74 \%$ das matrículas em cursos de graduação presenciais no Brasil, a maior parte em instituições não universitárias, ${ }^{2}$ sobretudo em cursos noturnos. Tais instituiçôes apresentam, em geral, situação mais precária para a oferta dos cursos. Devido ao menor custo de oferta, as licenciaturas são, historicamente, privilegiadas por essas instituições. A maior parte dos professores no Brasil, portanto, é formada em instituições não universitárias e em cursos ofertados no período noturno.

Há também uma forte tradição disciplinar no país que impede soluções que envolvam um caráter mais interdisciplinar na formação, vinculado ao campo da prática curricular da escolarização básica. E, 
ainda, o processo de oferta dos cursos permite inferir que as condições de formação dos professores, de modo geral, ainda estão distantes de serem satisfatórias, pela ausência de um desenho mais claro do perfil profissional a ser atingido, vinculado de forma mais orgânica ao campo da prática docente (Gatti \& Barretto, 2009).

Observa-se, hoje, grande pressão para que os professores apresentem melhor desempenho, principalmente no sentido de os estudantes obterem melhores resultados nos exames nacionais e internacionais. As críticas ressaltam, sobretudo, os professores como mal formados e pouco imbuídos de sua responsabilidade pelo desempenho dos estudantes. A partir daí, os diversos níveis governamentais vêm criando mecanismos que visam ampliar o controle do exercício profissional, mediante exames de certificação de competência, associados à implantação de incentivos financeiros. ${ }^{3}$ Tais medidas, no entanto, se não totalmente dispensáveis, precisam ser relativizadas frente aos salários nada compensadores, carreiras que não oferecem clareza de percurso, imaginário coletivo desmotivado em relação à profissão, alto índice de abandono da docência e a progressiva queda na procura pelos cursos de licenciatura. Revela-se um cenário que exige assumir prioridades para tornar a ocupação não apenas mais atrativa e valorizada, mas também mais competente para o desenvolvimento de uma educação com qualidade para todos.

Os marcos legais: o embate entre a centralização e a descentralização no que diz respeito às políticas de valorização e formação docente

Embora a legislação nacional (Constituição Federal de 1988 e Lei de Diretrizes e Bases da Educação Nacional de 1996) aponte para a necessidade de garantir planos de carreira, piso salarial nacional para os profissionais da educação, estabelecimento de estatutos e planos de carreira do magistério público e obrigatoriedade de formação superior para todos os docentes, a Constituição reafirmou, paralelamente, a condição do país como uma República Federativa e o reconhecimento dos municípios, inclusive, como entes federativos. Tal fato colocou em destaque o princípio da descentralização e, com isso, o campo educacional e todas as açôes que dizem respeito aos docentes da escolarização básica passam a depender, cada vez mais, da organização dos diversos entes federativos em regime de colaboração. 
Valorização e formação dos professores para a educação básica...

Todavia, esse regime não se encontra suficientemente estabelecido e regulamentado no país. Serve, ao mesmo tempo, para permitir demasiada descentralização em determinadas responsabilizaçôes, e centralizaçôes talvez excessivas em outras. A reestruturação da participação da União na área da educação e da valorização e formação dos profissionais docentes tem sido de caráter sobretudo centralizado, o que foi sendo explicitado a partir da aprovação da própria LDB/96 e de outras legislaçōes, tais como a criação do Fundo de Manutenção e Desenvolvimento do Ensino Fundamental e Valorização do Magistério (FUNDEF), pela Lei n. 9.424/1996, posteriormente transformado em Fundo de Manutenção e Desenvolvimento do Ensino Básico e Valorização do Magistério (FUNDEB), pela Lei n. 11.494/2007. Este fundo estabelece a perspectiva de per capita mínimos para cada etapa da educação básica e oferece a todas as etapas, da creche ao ensino médio, o beneficiamento de recursos federais, compromisso da União com este nível de escolarização que se estenderá até 2020.

As leis apontadas dão papel e força ao Executivo federal, que dita, em grande parte, as normas para a redefinição de responsabilidades no que diz respeito à oferta do ensino, controle de qualidade, de avaliação e de definição de padrōes curriculares. Assim, o Ministério da Educação instituiu as Diretrizes Curriculares Nacionais para a Formação Inicial de Professores para a Educação Básica em Nível Superior (Resolução CNE/CP n. 1, 2002), com a finalidade de estabelecer critérios para a seleção dos conteúdos que devem constituir esta formação, que tem sido tratada, cada vez mais, como elemento nuclear das reformas educacionais.

Mais recentemente, o MEC instituiu, por meio do Decreto $\mathrm{n}$. 6.755, de janeiro de 2009, a Política Nacional de Formação de Profissionais do Magistério da Educação Básica. Este documento, além de manter a responsabilidade da Coordenação de Aperfeiçoamento de Pessoal de Nível Superior (CAPES) pelo fomento a programas de formação inicial e continuada no país, estabeleceu a criação dos Fóruns Estaduais de Apoio à Formação dos Profissionais da Educação. Na esteira desta política foi constituído, igualmente, o Plano Nacional de Formação de Professores da Educação Básica (PARFoR) (Brasil/MEC, 2009), com o objetivo de estabelecer ações e metas para a qualificação dos 600 mil professores brasileiros que ainda não possuem a formação considerada adequada ao trabalho que exercem.

Falta, todavia, para dar consequência às medidas já tomadas, avançar na questão do regime de colaboração entre os entes federados. O PNE 
e suas definições podem constituir um caminho para a construção da articulação e colaboração necessária à consolidação de ações que estão projetadas, inclusive pelo PARFOR, cuja finalidade é atender à demanda por formação inicial e continuada dos professores das redes públicas. Os entes federados não estão, contudo, suficientemente articulados na execução das políticas públicas destinadas ao desenvolvimento de tais objetivos, necessários para a valorização docente, por meio de uma formação mais articulada e planejada dos quadros para o magistério.

Outras iniciativas foram constituídas recentemente com a finalidade de valorizar o campo profissional, ainda que em patamares incipientes, tais como a Lei do Piso Salarial (Brasil, 2008) e, mais recentemente, as Diretrizes Nacionais para os Planos de Carreira e Remuneração dos Profissionais do Magistério da Educação Básica (Brasil/MEC/CNE, 2009). Contudo, é na formação docente que encontramos hoje o foco central das políticas nacionais ocorridas no cenário da educação brasileira desde a década de 1990. O professor, tido como agente de mudança, emerge, pois, cada vez mais, como o responsável pela realização do ideário do século XXI.

A reestruturação da participação da União na valorização e formação dos profissionais docentes requer, todavia, a existência um Sistema Nacional de Educação regulamentado e realmente articulado, reivindicação hoje enfatizada pelo movimento organizado dos educadores, bem como pelas conferências nacionais realizadas nos dois últimos anos. Nestas conferências, encontramos também a reivindicação por um Fórum Nacional de Educação e pela sistematização das Conferências Nacionais como práticas do Estado (CONAE, 2010).

Algumas prioridades para o desenvolvimento da valorização e formação dos professores para a educação básica no novo PNE

\section{A indissociabilidade entre valorização, formação e outras condições para o desenvolvimento do trabalho docente}

Cabe ao novo PNE intermediar ações que integrem estes aspectos de dimensôes diferenciadas do trabalho docente, porém indissociáveis (cf. CONEB, 2008; CONAE, 2010). Ao lado de estratégias políticas consistentes, coerentes e contínuas de formação inicial e continuada dos professores, precisam ser melhoradas as suas condições de trabalho, de carreira e de 
Valorização e formação dos professores para a educação básica...

remuneração. É, pois, numa perspectiva social e de competência técnica e política do trabalho docente que entendemos a prospecção das ações para o novo PNE.

Tal perspectiva de constituição do trabalho docente relaciona-se ao movimento pela democratização da sociedade, que foi especialmente retomado por estudos e discursos políticos no início da década de 1980 , momento da gradativa ampliação do novo modelo socioeconômico e político da era global. Por meio das suas diversas associações, ${ }^{4}$ os educadores firmaram determinadas bandeiras de luta que persistem hoje como princípios para a constituição do trabalho docente na perspectiva da transformação social. Deriva daí o incentivo a centrar nas faculdades e centros de educação das universidades o lócus formativo orientador da formação dos professores, bem como a insistência na construção do docente como um intelectual, com autonomia para entender as bases políticas que sustentam o seu trabalho "e para enfrentar uma das características fundamentais da prática educativa: sua ambiguidade, seus conflitos de valores e a permanente necessidade de reinterpretar as situaçôes para elucidar o moralmente correto, mais do que o eficaz" (Contreras, 2002, p. 264).

Os princípios apontados são encontrados nas reivindicações que os educadores fazem nas conferências nacionais já referenciadas e que encontramos, também, no documento apresentado em 2009 pelo Conselho Nacional de Educação, anexo à Portaria CNE/CP n. 10/2009, denominado "Indicações para subsidiar a construção do Plano Nacional de Educação 2011-2020”. Sua presença pode ser encontrada igualmente na coletânea "Mais dez: o legislativo e a sociedade construindo juntos o novo Plano Nacional de Educação: uma nova educação para um novo Brasil propostas para o PNE, 2011-2020", organizada pela Comissão de Educação e Cultura da Câmara dos Deputados, pelo CNE e pela Confederação Nacional do Comércio de Bens, Serviços e Turismo (2010).

\section{A necessidade de avançar no sentido de uma formação voltada para o modelo pedagógico-didático dos professores, como forma de combater a exclusão}

O PNE tem como uma das suas tarefas primordiais aprofundar a articulação da formação inicial com a formação continuada, o que envolve destacar a busca constante da relação entre os locais de formação, 
sistemas de ensino e escolas básicas. Destaca-se nesta articulação o papel dos centros, institutos e faculdades de Educação.

Segundo Saviani (2009), configuram-se dois grandes modelos de formação de professores: o modelo dos conteńdos culturais cognitivos, no qual a formação dos professores situa-se e se esgota na cultura geral e no domínio específico dos conteúdos da área de conhecimento para a qual o docente é preparado, e o modelo pedagógico didático, que considera que a formação só se completa com o preparo pedagógico-didático do professor. O autor destaca o caráter antielitista do modelo pedagógico-didático por centralizar sua preocupação na socialização do conhecimento, nas possibilidades de ensinar tudo a todos: “(...) o modelo pedagógicodidático pressupõe, desde Comenius, que todo e qualquer conteúdo, quando considerado adequadamente à vista das condiçôes do ser que aprende, é suscetível de ser ensinado a todos os membros da espécie humana" (Saviani, 2009, p. 149). Tal consideração pode ser lembrada para reforçar a urgência em implementar as diretrizes curriculares para a formação de professores da educação básica (Resolução do CNE/CP n. 1/ 2002), mesmo que estas requeiram ainda reconfiguraçōes na sua proposta para o atendimento daquilo que consideramos como uma formação para a inclusão.

$\mathrm{O}$ atual enquadramento legal da formação de professores, a partir da LDB/1996, traz pressupostos e orientaçōes para a organização e desenvolvimento dos cursos de licenciatura que rompem com uma tradição iniciada no país em 1934, quando foram criados os primeiros cursos superiores de formação de professores, por meio do modelo denominado de " $3+1$ " (três anos de conteúdos específicos da respectiva área do conhecimento e um das chamadas disciplinas pedagógicas). Esta concepção encontra-se ainda impregnada nos processos de formação de professores, com base na crença de que esta se esgota no domínio de conteúdos específicos da disciplina que o professor irá lecionar. Os professores envolvidos com a formação pedagógica dos futuros docentes e que devem transformar os estudantes em profissionais da educação convivem com a insatisfação e com a compreensão de que não basta a superposição de conteúdos pedagógicos para uma formação, na qual a prática educativa deve fundamentar o processo de formação docente.

Os atos legais emanados do CNE, que sucederam a LDB/1996, representaram um avanço importante, ao estabelecer uma configuração específica aos cursos de licenciatura, distinguindo-os, de certa forma, 
Valorização e formação dos professores para a educação básica...

dos cursos de bacharelado 5 e aproximando-os mais do "modelo pedagógico-didático". Segundo Bordas (2009), a nova configuração favorece, potencialmente, o aprofundamento da discussão sobre aspectos teórico-práticos desta formação e precisa ser mais enfaticamente estabelecida. A implantação das atuais diretrizes nos cursos de formação de professor, no entanto, encontra problemas também no que diz respeito à articulação entre o processo formador conduzido pelas IES e o trabalho das escolas de educação básica, hoje apenas enfatizado na realização dos Estágios Supervisionados de Docência.

O processo de implementação das diretrizes para a formação docente no país requer continuidade e acompanhamento. Estudos realizados recentemente por Bordas (2009), Gatti e Barreto (2009) e Scheibe (2009) sobre a implementação das novas diretrizes nos cursos de licenciatura, em diversas áreas de conteúdos, indicam que boa parte dos cursos ainda não mantém correspondência clara com as determinaçōes legais contidas nos pareceres e nas resoluçōes sobre as diretrizes para as licenciaturas. Parece imperativo, neste sentido, buscar estratégias e definiçôes políticas que reforcem institucionalmente os cursos de licenciatura, a partir de uma análise mais aprofundada do conteúdo dos projetos pedagógicos implementados a partir das Diretrizes Curriculares. Importa ter presente que a possibilidade de aperfeiçoamento dos currículos destes cursos não se esgota nos aspectos pedagógicos stricto sensu, mas supōe, sobretudo, estratégias de articulação entre os diversos institutos/departamentos que participam da formação e as faculdades de Educação, de modo que, internamente, nas instituiçōes formadoras, aconteça a integração.

Outras reivindicações importantes indicadas nos documentos finais já referenciados cabem ser lembradas, no sentido da melhoria da formação docente, tais como: garantir maior financiamento público para ampliar vagas nas instituiçóes, especialmente as públicas, para cursos de licenciatura e pós-graduação; criar programas de bolsas para alunos de licenciatura, com destaque à existência de um plano emergencial para a área das licenciaturas nas Ciências Exatas; ampliar e democratizar a distribuição de bolsas para professores da rede pública em nível de mestrado e doutorado, garantindo a licença remunerada durante o período que estiverem cursando, sem prejuízo funcional e com o estabelecimento de critérios contidos no plano de cargos, carreiras e salários; proporcionar formação continuada a todos os profissionais em 
exercício nas diversas modalidades da educação básica; ampliar também a oferta de cursos de pós-graduação lato sensu e stricto sensu voltados para a formação de gestores e administradores da educação, orientadores educacionais, supervisores/coordenadores pedagógicos, entre outros; implementar, em todos os programas de formação inicial de professores, a discussão sobre novas tecnologias, gênero e diversidade étnico-racial, bem como sobre sustentabilidade ambiental; sedimentar os polos da Universidade Aberta do Brasil (UAB) em centros de formação continuada dos profissionais da educação, coordenados pelas universidades, em parceria com as redes de ensino público.

É importante buscar a superação da formação continuada com base em cursos rápidos e sem conexão com o projeto político-pedagógico da escola, para promover a reflexão permanente do professor. Nesse sentido, a escola e seu cotidiano constituem-se, ao lado das instituições formadoras de professores, em ambiente formativo que necessita de ações e programas sistematizados em períodos específicos e com clara articulação à carreira docente. $\mathrm{O}$ documento da CONAE (2010) ressalta, especialmente, a necessidade de articular ações formativas que superem soluçóes apenas emergenciais.

A efetivação de plano de carreira e remuneração para o magistério, no sentido da melhoria do trabalho docente

Os entes federados estão longe de cumprir com o que a legislação já requer como mínimo. É o que sucede hoje com a Lei n 11.738/2008, que estabelece um piso salarial, profissional e nacional de 950 reais para uma jornada de 40 horas semanais, e que deveria ter sido implantado progressivamente até janeiro de 2010, com obrigatoriedade de reajustes anuais. Mesmo esta exigência mínima, que toma por base o pagamento para professores formados nos cursos de nível médio, é questionada por parte de alguns governantes estaduais, que entraram com uma Ação Direta de Inconstitucionalidade que fez com que o Supremo Tribunal Federal suspendesse temporariamente alguns dispositivos da lei.

Mais recentemente, a Resolução CNE/CEB n. 2/2009 fixou Diretrizes Nacionais para os Planos de Carreira e Remuneração dos Profissionais do Magistério ${ }^{6}$ da Educação Básica Pública, cuja implementação certamente será um dos grandes desafios para o próximo decênio. É oportuno, frente ao necessário cumprimento das diretrizes e normas já 
Valorização e formação dos professores para a educação básica...

estabelecidas e que representam bandeiras históricas dos movimentos docentes, que o PNE incorpore decisão da CONAE que diz respeito à proposição de um código de responsabilidade educacional, para que estes e outros aspectos da gestão democrática pública possam ter continuidade, independentemente das mudanças de governo. Dentre outras prioridades vinculadas ainda ao trabalho docente e apresentadas à consideração para um novo PNE, podemos destacar: a necessária redução da carga horária do professor, sem perda salarial, para aqueles que participam de programas de formação inicial; criar dispositivos legais que garantam a aplicação da dedicação exclusiva dos docentes em uma única instituição de ensino; estipular um número máximo de alunos por turma e por professor: (1) na educação infantil: de 0-2 anos, seis a oito crianças por professor; de 3 anos, até 15 crianças por professor; de 4-5 anos, até 20 crianças por professor; (2) no ensino fundamental: nos anos iniciais, 25 alunos por professor; nos anos finais, 30 alunos por professor; (3) no ensino médio e na educação superior, até 35 alunos por professor.

\section{Limites à educação a distância}

Ao novo PNE cabe cumprir com as determinações firmadas nas conferências a respeito da educação a distância (EaD). Com base no princípio da formação com qualidade, os delegados firmaram a posição de exigir que a formação inicial de professores (cursos de graduação e normais de nivel médio) seja oferecida na modalidade presencial.

O crescimento de cursos na modalidade EaD ocorrido na última década causa preocupação não só entre os estudiosos da educação, particularmente aqueles da formação de professores, mas também em toda a comunidade vinculada à escolarização. A tardia regulação da oferta da EaD facilitou a abertura desmesurada desses cursos, a ponto de terse estabelecido, em muitas situações, uma clara e danosa concorrência em relação aos cursos presenciais.

Há uma compreensão de que a formação indiscriminada desenvolvida a distância na qualificação dos profissionais para o magistério traz privações vinculadas à vivência universitária, comunitária e institucional que compõem um processo formativo. Grupos organizados, vinculados a programas de EaD, tentam minimizar os obstáculos à realização de programas de formação em nível de graduação, mas a maioria dos participantes da CONAE votou pela sua excepcionalidade, de modo a 
ser utilizada na formação inicial de professores apenas em situações em que a modalidade presencial não atinge a população que precisa ser formada.

Na CONEB (2008) já fora aprovada decisão de que a formação inicial de professores deveria ser feita preferencialmente em cursos presenciais. Na CONAE (2010), no entanto, tal indicação pareceu ainda frágil à maioria dos delegados, que decidiram por uma definição mais mandatória: a formação inicial deverá ser presencial e, somente excepcionalmente, a distância. Espera-se, assim, que as regulamentaçóes para a próxima década façam valer esta determinação coletiva que vai no sentido de não abrir mão da presença de um cotidiano coletivo de estudos e relaçóes escolares no processo de preparação inicial dos quadros para o magistério no país.

É desejável a inserção cada vez maior das novas tecnologias da informação e do seu conhecimento nos processos formativos de docentes como ação integrada a um conjunto de ações formativas presenciais, para contribuir com a democratização do acesso a novos espaços e ações de formação, proporcionando mais flexibilidade na organização e desenvolvimento dos estudos. Assim, requerem-se locais formativos dotados de equipamentos de informática, sem descuidar, no entanto, da ampliação das suas bibliotecas, laboratórios e salas de aula.

\section{O estabelecimento de prazo para a extinção do curso Normal de nivel médio no pais}

Formar todos os docentes em nível superior é uma meta a ser alcançada. O curso Normal de nível médio, destinado à formação dos professores para a educação infantil e anos iniciais do ensino fundamental, constituiu-se numa questão polemizada na CONAE. A sua manutenção como local de formação dividiu e divide a posição dos educadores, particularmente, por encontrar na Confederação Nacional dos Trabalhadores da Educação (CNTE) e no peso deste coletivo posição favorável à sua permanência. A conveniência desta posição, no entanto, precisa ser questionada. Duas razões têm sido apontadas para a sua defesa: (1) a alegação da impossibilidade de, a curto prazo, dar conta de formar todos os docentes em nível superior, particularmente aqueles que se destinam à educação infantil e aos anos iniciais do ensino fundamental; (2) uma tradição de estudos mais voltados à prática docente 
Valorização e formação dos professores para a educação básica...

(instrumental) nos cursos de nível médio do que a dos cursos de pedagogia. É preciso considerar, no entanto, que tais razões não podem estar acima da compreensão de que é necessário aprimorar o estudo dos que se formam como docentes e que uma formação básica integral anterior ao início do processo de profissionalização não é dispensável.

A indicação vencedora entre os delegados da CONAE, que dá base à continuidade da existência do curso Normal de ensino médio, mantém o que está definido na $\mathrm{LDB} / 96$, no seu artigo 62, que considera como “(...) formação mínima para o exercício do magistério na educação infantil e nas quatro primeiras séries do ensino fundamental, a oferecida em nível médio, na modalidade Normal". Também a Lei $n$. $12.014 / 2009$, que altera o artigo $61 \mathrm{da}$ LDB/2006, com a finalidade de discriminar as categorias de trabalhadores que se devem considerar profissionais da educação, considera como profissionais da educação aqueles "habilitados em nível médio ou superior para a docência na educação infantil e nos ensinos fundamental e médio". Tal posição, no entanto, adia o cumprimento de um dos elementos-chave para a valorização e formação dos docentes. Nesse sentido, a posição apresentada no documento do CNE para subsidiar o PNE parece ser pertinente: estabelecer com o PNE um prazo para extinção do curso como possibilidade de qualificação do professor para a educação infantil e para os anos iniciais da educação fundamental. Tal reivindicação é necessária para que se possa atingir um patamar mais aprimorado de formação docente. Eis mais um desafio para o planejamento das açóes educacionais da próxima década.

\section{Avaliação da formação e da ação docente}

A avaliação da formação e da ação do quadro do magistério é fundamental para complementar o processo que visa a qualidade social da educação. A partir de uma autoavaliação institucional, em todos os sistemas de ensino, com critérios definidos nacionalmente, podem ser identificadas, por exemplo, lacunas na formação inicial, passíveis de serem sanadas pelo desenvolvimento de um programa de formação continuada, assim como aspectos com potencial para a melhoria dos profissionais de educação.

Para que, efetivamente, contribua para a formação e a valorização profissional, o processo avaliativo requer um caráter participativo, 
fundamentado em princípios éticos, democráticos, autônomos e coletivos. É relevante, portanto, a implantação de um sistema de avaliação institucional que tenha como perspectiva também subsidiar as ações de formação continuada, com vistas à melhoria do desempenho funcional e à progressão na carreira e que não se constitua, particularmente, em instrumento de punição dos profissionais da educação. Nesse sentido, cabe incentivar processos avaliativos na linha de uma avaliação processual e diagnóstica, utilizada como instrumento para identificação das necessidades do sistema educacional, superando desigualdades nas condições de trabalho e aprendizagem.

É desejável a constituição de uma comissão nacional de formação dos profissionais da educação para acompanhar os processos de criação, credenciamento e autorização de cursos, além de sua avaliação permanente. Cabe, atualmente, interrogar e discutir de forma mais aprofundada as avaliações em larga escala que estão sendo realizadas e a sua implementação na área da formação docente, para que não se constituam como mais uma forma de exclusão e controle de estudantes e professores.

\section{Considerações finais}

Parte dos debates e propostas aprovadas durante as Conferências Nacionais de Educação - CONEB (2008) e CONAE (2010) -, bem como, ainda, das propostas apresentadas pelo Conselho Nacional de Educação não são formulaçôes novas. Muitos dos preceitos defendidos pelos participantes dos eventos fazem parte de formulações construídas nos movimentos dos educadores, ao longo das últimas décadas, e mesmo de preceitos que a própria legislação já determina mas que não são cumpridos. Entretanto, há ainda muito por fazer em termos de ações a serem planejadas e executadas, e de legislação ordinária a ser estabelecida para a melhoria das condiçóes do trabalho docente no país.

As demandas por formação adequada necessitam do apoio do poder central para levá-las a bom termo. Saltam à vista tanto a pertinência de adoção de uma estratégia de ação articulada entre as diferentes instâncias que formam professores e as que os admitem como docentes, como também a distribuição desigual da oferta pública dos cursos superiores de formação para a docência, no interior de cada região do país. 
Valorização e formação dos professores para a educação básica...

As ações articuladas, já iniciadas nos últimos anos pelo desempenho do Plano Nacional de Formação de Professores da Educação Básica (PARFOR), são promissoras e é desejável que haja uma estratégia de continuidade particularmente na organização dos planos estratégicos de formação inicial e continuada que estão sendo acordados nos Fóruns Estaduais Permanentes de Apoio à Formação Docente. A partir deste Plano, forma-se hoje um regime de colaboração entre as secretarias de Educação dos estados e municípios e as instituições públicas de educação superior, neles sediadas, para ministrar cursos gratuitos a professores que estão em exercício nas escolas públicas e que não possuam ainda a formação adequada à lei estabelecida.

A fim de cumprir o Decreto n. 6.755, o MEC delegou à CAPES a responsabilidade pela indução, fomento e avaliação dos cursos no âmbito do PARFOR. Todas as licenciaturas das áreas de conhecimento da educação básica poderão ser ministradas nas modalidades presencial e a distância: cursos de primeira licenciatura para professores sem graduação, de segunda licenciatura para licenciados que atuam fora da sua área de formação, e de formação pedagógica para bacharéis atuantes no ensino.

Com estas medidas, o MEC prevê uma oferta superior a 400 mil novas vagas, envolvendo cerca de 150 instituições de educação superior (federais, estaduais, comunitárias e confessionais) nos estados que aderiram à formação. Os cursos foram iniciados no segundo semestre de 2009 e terão continuidade em 2010 e 2011 . A participação dos professores é feita por meio de uma pré-inscrição, cadastrando seu currículo na Plataforma Paulo Freire, sistema informatizado criado para este fim. Em contrapartida aos recursos adicionais do MEC para a formação, os sistemas estaduais e municipais devem ainda fornecer suporte aos professores cursistas em exercício, em parceria com as instituições de educação superior.

Vê-se que há um grande movimento nas políticas públicas com vistas a suprir a defasagem de formação e de valorização do trabalho docente. Mesmo assim, as dificuldades e os embates continuam sendo inúmeros. Cabe ao novo PNE estabelecer prioridades para dar continuidade às ações que superem a defasagem existente, corrigindo, para isso, determinados percursos e introduzindo novas iniciativas com base nas formulaçôes já destacadas pelos coletivos de educadores.

Recebido e aprovado em agosto de 2010. 


\section{Notas}

1. A formação de professores/as no Brasil, no contexto atual, ocorre em cinco formatos institucionais: 1) nas escolas normais, que ainda oferecem o curso de magistério/normal de nível médio; 2) nas universidades, que oferecem os cursos de licenciatura; 3) nas IES em geral, ou seja, nos centros universitários, faculdades integradas ou faculdades, institutos, centros e escolas que oferecem cursos de licenciatura em geral; 4) nos institutos superiores de educação, criados pela LDB, para funcionar no interior das IES e para assumir toda a formação inicial e continuada de professores/as; 5) nos centros federais de educação tecnológica (CEFETs) ou institutos federais de educação tecnológica (IFETS), que podem ofertar os atuais cursos de licenciatura, além de licenciaturas específicas para a educação profissional.

2. A organização da educação superior no Brasil envolve duas grandes categorias: as instituições universitárias (universidades) e as não universitárias, tais como os centros universitários, centros federais de educação tecnológica, institutos federais de educação, ciência e tecnologia e estabelecimentos isolados de ensino superior.

3. Além dos exames internacionais, foram criados no Brasil, nas últimas décadas, em âmbito federal e estadual, exames e provas que visam a aferir o desempenho das escolas, dos alunos e dos professores, o que efetivamente vem aumentando a pressão para que os professores apresentem maior desempenho.

4. Associação Nacional pela Formação dos Profissionais da Educação (ANFOPE); Associação Nacional de Política e Administração Escolar (ANPAE); Associação Nacional de Pós-Graduação e Pesquisa em Educação (ANPEd); Centro de Estudos Educação e Sociedade (CEDES); Fórum de Diretores das Faculdades de Educação (FORUMdir).

5. Desde 2005, esta diferenciação deveria estar contemplada nos projetos de curso das licenciaturas, uma vez que as Diretrizes Curriculares Nacionais foram aprovadas pelo CNE entre os anos de 2001 e 2004, com vistas a orientar os cursos de graduação que se ocupam da formação de professores para as diferentes áreas de conhecimento inseridas nos currículos da educação básica.

6. São considerados profissionais do magistério aqueles que desempenham as atividades de docência ou as de suporte pedagógico à docência, tais como direção ou administração, planejamento, inspeção, supervisão, orientação e coordenação educacionais, exercidas no âmbito das unidades escolares de educação básica, em suas diversas etapas e modalidades, e com a formação mínima determinada pela legislação federal de Diretrizes e Bases da Educação Nacional (Resolução CNE/CEB n.2/2009, art. $2^{\circ}, \$ 1^{\circ}$ ).

\section{Referências}

BORDAS, M. Subsidio à formulação e avaliação de políticas educacionais brasileiras: avaliação da implantação das diretrizes curriculares nacionais para a formação de professores nos cursos de licenciatura. Brasília, DF: CNE/UNESCO, 2009. (Relatório de pesquisa).

BRASIL. Câmara dos Deputados. Comissão de Educação e Cultura (CEC). Mais dez: o legislativo e a sociedade construindo juntos o novo Plano Nacional de Educação: uma nova educação para um novo Brasil; propostas para o PNE, 2011-2020. Brasília, DF: SENAC ; CNE; SESC, 2010. 
Valorização e formação dos professores para a educação básica...

BRASIL. Decreto n. 6.755, de 29 de janeiro de 2009. Institui a Política Nacional de Formação de Profissionais do Magistério da Educação Básica, disciplina a atuação da Coordenação de Aperfeiçoamento de Pessoal de Nível Superior - CAPES no fomento a programas de formação inicial e continuada, e dá outras providências. Diário Oficial da União, Brasília, DF, 30 jan. 2009. Disponível em: <http://www:planalto.gov.br/ccivil_03/ _Ato2007-2010/2009/Decreto/D6755.htm>. Acesso em: 8 jun. 2010.

BRASIL. Lei n. 9.394, de 20 de dezembro de 1996. Estabelece as diretrizes e bases da educação nacional. Diário Oficial da Uniāo, Brasília, DF, 23 dez. 1996.

BRASIL. Lei n. 9.424, de 24 de dezembro de 1996. Dispõe sobre o Fundo de Manutenção e Desenvolvimento do Ensino Fundamental e de Valorização do Magistério, na forma prevista no art. $60, \$ 7^{\circ}$, do Ato das Disposiçóes Constitucionais Transitórias, e dá outras providências. Diário Oficial da União, Brasília, DF, 26 dez. 1996. Disponível em: <http://www.planalto.gov.br/ccivil_03/Leis/L9424.htm>.

BRASIL. Lei n. 10.172, de 9 de Janeiro de 2001. Aprova o Plano Nacional de Educação (2001-2010) - PNE e dá outras providencias. Diário Oficial da União, Brasília, DF, 10 jan. 2001. Disponível em: <http:// www.planalto.gov.br/ccivil_03/leis/leis_2001/110172.htm>.

BRASIL. Lei n. 11.494, de 20 de junho de 2007. Regulamenta o Fundo de Manutenção e Desenvolvimento da Educação Básica e de Valorização dos Profissionais da Educação - FUNDEB, e dá outras providências. Diário Oficial da Uniāo, Brasília, DF, 21 jun 2007. Disponível em: <http://www.planalto.gov.br/ccivil_03/Leis/L11.494.htm>.

BRASIL. Lei n. 11.738, de 16 de julho de 2008. Regulamenta a alínea "e" do inciso III do caput do art. 60 do Ato das Disposições Constitucionais Transitórias, para instituir o piso salarial profissional nacional para os profissionais do magistério público da educação básica. Diário Oficial da União, Brasília, DF, 17 jul 2008. Disponível em: <http:// www.planalto.gov.br/ccivil_03/Leis/L11.738.htm>.

BRASIL. Lei n. 12.014, de 6 de agosto de 2009. Altera o art. 61 da Lei n. 9.394, de 20 de dezembro de 1996, com a finalidade de discriminar as categorias de trabalhadores que se devem considerar profissionais da 
educação. Diário Oficial da Uniāo, Brasília, DF, 07 ago 2009. Disponível em: <http://www.planalto.gov.br/ccivil_03/_Ato2007-2010/2009/ Lei/L12014.htm>.

BRASIL. Ministério da Educação. Portaria Normativa n. 9, de 30 de junho de 2009. Institui o Plano Nacional de Formação dos Professores da Educação Básica no âmbito do Ministério da Educação. Brasília, DF: MEC, 2009.

BRASIL. Ministério da Educação. Conselho Nacional de Educação. Parecer CNE/CP n. 9, de 8 de maio de 2001. Diretrizes Curriculares Nacionais para a Formação de Professores da Educação Básica, em nível superior, Curso de Licenciatura, de graduação plena. Diário Oficial da Uniāo, Brasília, DF, 18 jan. 2002, seção 1, p. 31. Disponível em: $<$ http://portal.mec.gov.br/cne/arquivos/pdf/009.pdf>.

BRASIL. Ministério da Educação. Conselho Nacional de Educação. Portaria CNE/CP n. 10, de 6 de agosto de 2009, que dá publicidade ao documento produzido pela Comissão Bicameral constituída pelas Portarias CNE/CP n. 7/2009 e n. 8/2009, contendo indicaçōes para subsidiar a construção do Plano Nacional de Educação 2011-2020. Brasília, DF: MEC/CNE, 2009.

BRASIL. Ministério da Educação. Conselho Nacional de Educação. Resolução CNE/CP n. 1, de 18 de fevereiro de 2002. Institui Diretrizes Curriculares Nacionais para a Formação Inicial de Professores para a Educação Básica em Nível Superior, Curso de Licenciatura, de graduação plena. Disponível em: <http://portal.mec.gov.br/cne/arquivos/pdf/ rcp01_02.pdf>.

BRASIL. Ministério da Educação. Conselho Nacional de Educação. Resolução CNE/CEB n. 2, de 28 de maio de 2009. Fixa as Diretrizes Nacionais para os Planos de Carreira e Remuneração dos Profissionais do Magistério da Educação Básica Pública. Diário Oficial da União, Brasília, DF, 29 maio 2009, seção 1, p. 41-42. Disponível em: <http:// portal.mec.gov.br/dmdocuments/resolucao_cne_ceb002_2009.pdf>.

BRASIL. Ministério da Educação. Instituto Nacional de Estudos e Pesquisas Educacionais (INEP). Estudo exploratório sobre o professor brasileiro: com base nos resultados do Censo Escolar da Educação Básica 2007. Brasília, DF: MEC/INEP, 2009. 
Valorização e formação dos professores para a educação básica...

BRASIL. Ministério da Educação. Instituto Nacional de Estudos e Pesquisas Educacionais (INEP) Resumo Técnico do Censo da Educação Superior 2007. Brasília, DF, 2009b. Disponível em: <http://www.inep.gov.br/ download/superior/censo/2007/Resumo_tecnico_2007.pdf>.Acesso em: 14 maio 2010.

CONFERÊNCIA NACIONAL DE EDUCAÇÃO (CONAE), 2010, Brasília, DF. Construindo o Sistema Nacional Articulado de Educação: o Plano Nacional de Educação, diretrizes e estratégias; Documento Final. Brasília, DF: MEC, 2010. Disponível em: <http://conae.mec.gov.br/ images/stories/pdf/pdf/documetos/documento_final_sl.pdf>. Acesso em: 10 jun. 2010.

CONFERENCIA NACIONAL DE EDUCAÇÃO BÁSICA (CONEB), 1., 2008, Brasília, DF. Documento Final. Brasília, DF: MEC, 2008. Disponível em: <www.mec.gov.br>. Acesso em: 8 mar. 2010.

CONTRERAS, J. A autonomia de professores. Trad. de Sandra Trabucco Valenzuela. São Paulo: Cortez, 2002.

GATTI, B.; BARRETO, E.S.S. Professores do Brasil: impasses e desafios. Brasília, DF: UNESCO, 2009.

OLIVEIRA, D.A.; FELDFEBER, M. Politicas educativas y trabajo docente. Buenos Aires: Centro de Publicaciones Educativas y Material Didáctico, 2006.

OLIVEIRA, J.F. A articulação entre universidade e educação básica na formação inicial e continuada de professores: demandas contemporâneas, situação-problema e desafios atuais. 2010, 17p. (mimeo.).

SAVIANI, D. Formação de professores: aspectos históricos e teóricos do problema no contexto brasileiro. Revista Brasileira de Educação, Rio de Janeiro, v. 14, n. 40, p. 143-155, 2009.

SCHEIBE, L. Relatório final de pesquisa do projeto "Subsidio à Formulação e Avaliação de Políticas Educacionais Brasileiras: avaliação da implantação das diretrizes curriculares nacionais para o curso de Pedagogia”. Florianópolis: CNE/UnESCO, 2009. (meio digital). 